1 Changes in groundwater chemistry before two consecutive magnitude $>5$ \title{
earthquakes in Iceland
}

3 Alasdair Skelton ${ }^{1}$, Margareta Andrén ${ }^{1}$, Hrefna Kristmannsdottir ${ }^{2}$, Gabrielle Stockmann ${ }^{1}$, Carl-Magnus

4 Mörth ${ }^{1}$, Árny Sveinbjörnsdóttir ${ }^{3}$, Sigurjón Jónsson ${ }^{4}$, Erik Sturkell ${ }^{5}$, Helga Rakel Gudrunardottir ${ }^{1}$, Hreinn Hjartarson $^{6}$, Heike Siegmund ${ }^{1}$ and Ingrid Kockum ${ }^{7}$

1. Department of Geological Sciences, Stockholm University, 10691 Stockholm, Sweden

2. University of Akureyri, 600 Akureyri, Iceland

3. Institute of Earth Sciences, University of Iceland, 101 Reykjavík, Iceland

4. King Abdullah University of Science and Technology, Thuwal, Saudi Arabia

5. Department of Earth Sciences, Gothenburg University, 40530 Gothenburg, Sweden

6. Landsvirkjun, 103 Reykjavík, Iceland

7. Karolinska Institutet, Stockholm, Sweden

Changes in groundwater chemistry have been proposed as earthquake precursors. These include changes in radon count rates ${ }^{1-2}$, concentrations of dissolved elements $s^{3-5}$ and stable isotope ratios $s^{4-5}$. Other proposed precursors include changes in seismic wave velocities ${ }^{6}$, water levels in boreholes ${ }^{7}$, micro-seismicity $^{8}$ and shear wave splitting ${ }^{9}$. These phenomena have often been attributed to rock volume expansion $^{7,10,11}$. However, most studies of precursory phenomena lack sufficient data to rule out other explanations unrelated to earthquakes ${ }^{12}$. For example, reproducibility has seldom been shown and few precursors have been statistically-evaluated. Here we show changes in stable isotope values and concentrations of dissolved elements preceding consecutive $M>5$ earthquakes, based on measurement of groundwater chemistry for five years from 2008 to 2013 in northern Iceland. We performed a statistical evaluation of these data, which shows that these chemical and isotopic changes are genuine anomalies and that these anomalies are associated with the consecutive $M>5$ earthquakes. Our results show that changes in groundwater chemistry before earthquakes can be statistically verified provided that measurement campaigns are sufficiently long term. This is an important step towards using groundwater chemistry as a tool in seismic hazard assessment.

We measured stable isotope ratios for hydrogen $\left(\delta^{2} \mathrm{H}\right)$ and oxygen $\left(\delta^{18} \mathrm{O}\right)$ and concentrations of dissolved major elements ( $\mathrm{Na}, \mathrm{Si}, \mathrm{Ca}$ and $\mathrm{K}$ ) in groundwater sampled weekly from a borehole at Hafralækur in northern Iceland (Fig. 1) since October 2008. This $100 \mathrm{~m}$ deep borehole penetrates 
basalt and basalt-derived sediments. It is flowing artesian, cased to $35 \mathrm{~m}$, with inlets at 65,82 and 96 $\mathrm{m}$ that yield a total of $7.7 \mathrm{I} . \mathrm{s}^{-1}$ of water. The water is hot $\left(73-76^{\circ} \mathrm{C}\right)$ and alkaline $(\mathrm{pH} 10.2)$ with a low content of dissolved solids (240 ppm), typical of low-temperature geothermal waters on the flanks of active rift zones in Iceland ${ }^{13}$. Previous studies suggest mixing of groundwater components equilibrated at different temperatures ${ }^{14}$ and/or groundwater components with different isotopic values $^{15-17}$. The latter are 1) modern day (Holocene) meteoric water $\left(\delta^{2} \mathrm{H} \sim-70 \%\right.$ at Hafralækur) ${ }^{16,17}$ and 2) pre-Holocene meteoric water, characterized by $\delta^{2} \mathrm{H}$ values that are considerably more negative than can be attributed to present day precipitation (i.e. $<-106 \%$ o) ${ }^{16,17}$. Water-rock interaction has also been inferred based on a shift from the global meteoric water line (GMWL) towards less negative $\delta^{18} \mathrm{O}$ values by up to $7 \%^{18}$ and changes in water chemistry indicating elevated temperatures ${ }^{13,14}$.

Earthquakes in northern Iceland primarily occur within an oblique transform zone linking the midAtlantic ridge in Iceland (Northern Volcanic Zone: Fig. 1) to its northwards continuation. Within this zone, most seismicity occurs along the Húsavík-Flatey Fault (HFF) and the Grímsey Oblique Rift (GOR). During our study, $M>5$ earthquakes occurred on October 21, 2012 (M 5.6) 78 km from Hafralaekur at the western end of the HFF (Fig. 1) and April 2, 2013 (M 5.5) $67 \mathrm{~km}$ from Hafralaekur within the GOR (Fig. 1). The first of these earthquakes was preceded by an M 4.5 earthquake on September 19, 2012 at the western end of the HFF.

Coulomb stress modeling shows that Hafralækur is too far from the hypocenters of both $M>5$ earthquakes to have experienced associated static stress changes exceeding tidal stresses ${ }^{19}$. However, Hafralækur is located within the region where, based on seismic energy density $(e)$ as an empirical metric ${ }^{20}$, co-seismic hydrological responses could occur in response to dynamic strain ${ }^{21}$ associated with both earthquakes $\left(e>10^{-3} \mathrm{~J}^{-\mathrm{m}^{-3}}\right)^{20}$. Also, Hafralækur is within the region where, based on other empirical estimates ${ }^{22,23}$, pre-seismic hydrological phenomena might have occurred.

Comparison of $\delta^{2} \mathrm{H}$ and $\delta^{18} \mathrm{O}$ of groundwater from Hafralækur with the GMWL (Fig. 2) reveals four clusters of data that are statistically separable with respect to $\delta^{18} \mathrm{O}\left(p\right.$-value $\left.<10^{-12}\right)$ but overlapping with respect to $\delta^{2} H$ (1-4: Fig. 2). For all four clusters, $\delta^{2} H$ values are much lighter than -106 \%o. For this reason, we infer that all samples contain a pre-Holocene component. Each cluster of data is elongated parallel to GMWL. This implies mixing between this pre-Holocene component and a modern day groundwater component (Fig. 2). Separation of data clusters is approximately parallel to the $\delta^{18} \mathrm{O}$ axis. This implies mixing with a third groundwater component that is affected by water-rock interaction (Fig. 2). This mainly affects $\delta^{18} \mathrm{O}$ because rocks contain abundant ( $>40 \%$ ) oxygen, but negligible $(<<1 \%)$ hydrogen. It may also involve a smaller negative $\delta^{2} \mathrm{H}$ shift related to formation of 
hydrous minerals ${ }^{24}$. Because fresh basaltic rocks have $\delta^{18} \mathrm{O}$ values $>+5 \%$, reaction with rocks can only explain $\delta^{18} \mathrm{O}$ shifts towards less negative values. For this reason, we argue that cluster 4 is least influenced by mixing with groundwater affected by water-rock interaction. This implies a large deuterium excess $\left(\delta^{2} \mathrm{H}-8 \times \delta^{18} \mathrm{O}\right)$ of $15.8 \pm 0.4 \%$, probably reflecting precipitation in a different climate regime ${ }^{17,25}$.

Because $\delta^{2} \mathrm{H}$ is only slightly affected by water-rock interaction, we use $\delta^{2} \mathrm{H}$ as a proxy for mixing between pre-Holocene and modern day groundwater components (Fig. 3a). We analyzed our $\delta^{2} \mathrm{H}$ data using the Shapiro-Wilk normality test and found that they are not normally distributed ( $p$-value $\left(10^{-6}\right)$, but become so ( $p$-value $>0.05$ ) after removal of the 21 most extreme (heavier) $\delta^{2} \mathrm{H}$ values. The extreme values define $\delta^{2} \mathrm{H}$ maxima that coincide with each $\mathrm{M}>5$ earthquake. Each maximum began before the respective earthquake and lasted 3 months. The remaining data are normallydistributed about a mean of $-126.6 \pm 2.7 \%$. Similarly, we used $\delta^{18} \mathrm{O}$ as a proxy for mixing with groundwater affected by water-rock interaction. We plotted deviation of $\delta^{18} \mathrm{O}$ from the GMWL, rather than from a fixed reference value (Fig. 3b), to remove the effect of (GMWL-parallel) mixing between pre-Holocene and modern day groundwater.

Gradual increases of $\delta^{2} \mathrm{H}$ from -126.6\% towards modern day (heavier) values began 6 and 2 months before the consecutive $M>5$ earthquakes (Fig. 3a), and culminated in maxima that are not part of a normal distribution. These maxima were followed by gradual returns towards pre-Holocene (lighter) values. We interpret mixing between pre-Holocene and modern day groundwater components. Aware that coincidence in timing is not proof of an association, we used a binomial test to calculate the probability that these $\delta^{2} \mathrm{H}$ maxima are related to the earthquakes as opposed to the null hypothesis that they occurred randomly. This approach has been used previously in similar studies ${ }^{26,27}$. We estimate a $p$-value of 0.003 for $\delta^{2} \mathrm{H}$ maxima lasting 3 months coinciding with both $\mathrm{M}$ $>5$ earthquakes and infer probable association on this basis.

There were multiple abrupt changes of $\delta^{18} \mathrm{O}$ throughout the study (Fig. 3b). There is also an overall trend of $\delta^{18} \mathrm{O}$ becoming more negative during the first 4 years of sampling (October $2008-$ September 2012). We infer stepwise reduction in the proportion of groundwater affected by waterrock interaction caused by switching between fracture pathways due to permeability changes. We further note that most earthquakes are followed by an abrupt change of $\delta^{18} \mathrm{O}$, but that these changes also occur at other times. With reference to a previous study, we propose that co-seismic permeability changes could have occurred in response to passing seismic waves ${ }^{21}$. 
These interpretations are corroborated by chemical ( $\mathrm{Na}$, Si and $\mathrm{Ca}$ ) data (Fig. 3c). The Shapiro-Wilk normality test shows that Na data are not normally distributed $\left(p\right.$-value $\left.<10^{-11}\right)$, but become so after removal of the 44 most extreme values. These values define concentration maxima not only for $\mathrm{Na}$ but also for Si and Ca that are statistically separable from the remaining data ( $p$-value $<10^{-5}$ ) and that coincide with each $M>5$ earthquake (Fig. 3c). Each maximum began before the respective earthquake and its duration was 4 months. The remaining chemical data are normally-distributed about linear gradients each of which shows steadily decreasing concentration during the first 4 years of sampling. With reference to previous studies, we propose that this reflects changes in the mixing ratio of groundwater components equilibrated with rock-forming minerals at different temperatures ${ }^{14,28}$. This is consistent with our interpretation based on stable isotope data of a progressive decrease in the proportion of a groundwater component that was more affected by water-rock interaction. Finally, we note that $\mathrm{K}$ behaves in an opposite manner to $\mathrm{Na}$, $\mathrm{Si}$ and $\mathrm{Ca}$ (supplementary table 1). This could reflect precipitation of K-bearing minerals in the source region of the groundwater that is more affected by water-rock interaction ${ }^{29}$. The binomial test gives a $p$-value of 0.005 for coincidence of concentration maxima of 4 months duration with both $M>5$ earthquakes. This argues for probable association with the earthquakes. Mixing of groundwater components is a probable cause of these maxima. Another possible cause is exposure of fresh rock surfaces to groundwater. Comparison with experimental studies ${ }^{30}$ infers that this could release cations (e.g. $\mathrm{Na}$, Ca) rapidly into solution.

Finally, we calculated $p$-values of $10^{-5}$ and 0.01 for both $\delta^{2} \mathrm{H}$ and concentration maxima coinciding with both $M>5$ earthquakes and for only one of these earthquakes, respectively. These compare with $p$-values $>0.10$ for probable association based on coincidence of one earthquake and one $\left(\delta^{2} \mathrm{H}\right.$ or $\mathrm{Na}$ ) maximum. We conclude that, for our time series, either two kinds of precursor or coincidence with two earthquakes are needed to demonstrate probable association.

In summary, we found evidence of three processes affecting groundwater chemistry at Hafralækur:

1) From October 2008 to September 2012, multiple abrupt changes of $\delta^{18} O$ accompanied by steadily decreasing concentrations of $\mathrm{Na}$, Si and $\mathrm{Ca}$ record a progressive decrease in the proportion of groundwater affected by water-rock interaction.

2) Both $M>5$ earthquakes coincided with $\delta^{2} \mathrm{H}$ maxima that are not part of a normal distribution ( $p$ value $\left.<10^{-6}\right)$. These began before each earthquake with a gradual increase of $\delta^{2} \mathrm{H}$ towards heavier values and ended with a gradual return towards lighter values. These observations can be explained by a gradual influx of modern day groundwater followed by dilution with pre-Holocene groundwater. 
Both earthquakes coincided with Na maxima that are not part of a normal distribution ( $p$-value $<10^{-}$ ${ }^{12}$ ). These correlate with Si and Ca maxima and began with a rapid increase of Na concentration before each earthquake. Possible causes are mixing of groundwater components or exposure of fresh rock surfaces to groundwater. Both changes can be explained by expansion of the rock volume (dilation) enhancing permeability. Dilation has previously been proposed to explain a wide range of phenomena thought to be precursory to earthquakes ${ }^{10,11}$.

3) Most earthquakes were followed by abrupt changes of $\delta^{18} \mathrm{O}$. These changes can be explained by different mixing ratios between groundwater variably affected by water-rock interaction. We attribute these changes to switching between fracture pathways caused by seismically induced changes of permeability.

Chemical and isotopic changes were reported before and after a M 5.8 earthquake in a study at Húsavík ${ }^{4,15}$ (Fig. 1). These changes differ from those reported in this study, mainly because groundwater sampled at Húsavík is from a deeper $(1220 \mathrm{~m})$ hotter $\left(94-110^{\circ} \mathrm{C}\right)$ source with a $10 \%$ marine component ${ }^{4,15}$.

Both $\mathrm{M}>5$ earthquakes coincided with $\delta^{2} \mathrm{H}$ and Na maxima that began before each earthquake and which are neither part of a normal distribution $\left(p\right.$-value $<10^{-6}$ ), nor occurred randomly ( $p$-value $=10^{-}$ $\left.{ }^{5}\right)$. These correlate with Si and Ca maxima. We conclude that $\delta^{2} \mathrm{H}$ and Na maxima are probable precursors to consecutive $M>5$ earthquakes. Both maxima can be explained by pre-seismic dilation. Although these changes are specific for Hafralækur, we infer that chemical and isotopic signals of dilation might be detected elsewhere before earthquakes. We make no claim of being able to predict earthquakes. Instead, we highlight groundwater chemistry as a promising target for future earthquake prediction studies. We note that Hafralækur is well-placed to study activity along the HFF, which has experienced prolonged seismic quiescence and is therefore considered at risk of a large (M 7) earthquake in the foreseeable future.

\section{References}

1. Ulomov, V.I. \& Mavashov, B.Z., On forerunners of strong tectonic earthquakes, Doklady Akademii Nauk SSSR 176 319-322 (1967).

2. Igarashi, G., Saeki, S., Takahata, N., Sumikaway, K., Tasaka, S., Sasaki, Y.,Takahashi, M. \& Sano, Y. Ground-water radon anomaly before the Kobe earthquake in Japan. Science 269, 60-61 (1995).

3. Tsunogai, U. \& Wakita, H. Precursory chemical changes in ground water: Kobe earthquake, Japan. Science 269, 61-63 (1995). 
4. Claesson, L., Skelton, A., Graham, C., Dietl, C., Mörth, C-M., Torssander, P. \& Kockum, I. Hydrogeochemical changes before and after a major earthquake. Geology 32, 641-644 (2004).

5. Reddy, D.V. \& Nagabhushanam, P., Chemical and isotopic seismic precursory signatures in deep groundwater: Cause and effect, Applied Geochemistry 27, 2348-2355 (2012).

6. Aggarwal, Y. P., Sykes, L. R., Simpson, D. W. \& Richards, P. G. Spatial and temporal variations of $\mathrm{V}_{\mathrm{S}} / \mathrm{V}_{\mathrm{P}}$ and in $\mathrm{P}$ wave residuals at Blue Mountain Lake, New York: Application to earthquake prediction. Journal of Geophysical Research 80, 718-732 (1973).

7. Roeloffs, E. Hydrologic precursors to earthquakes: a review. Pure and Applied Geophysics 126, 177209 (1988).

8. Stefánsson, R., Bonafede, M. \& Gudmundsson, G. B. Earthquake prediction research and the year 2000 earthquakes in the South Iceland Seismic Zone. Bulletin of the Seismological Society of America 101, 1590-1617 (2010).

9. Crampin, S. \& Zatsepin, S. V. Modeling the compliance of crustal rock: II. Response to temporal changes before earthquakes. Geophysical Journal International 129, 495-506 (1997).

10. Scholz, C. H., Sykes, L. R. \& Aggarwal, Y. P. Earthquake prediction: A physical basis. Science 181, 803-810 (1973).

11. Thomas, D. Geochemical precursors to seismic activity. Pure and Applied Geophysics 126, 241-266 (1988).

12. Ingebritsen, S., Sanford, W. \& Neuzil, C. Groundwater in Geologic Processes, 2nd edition (Cambridge University Press, Cambridge, 2006).

13. Kristmannsdóttir, H., Arnórsson, S., Sveinbjörnsdóttir, A.E., Ármannsson, H., Chemical variety of water in Icelandic heating systems. Proceedings of the World Geothermal Congress 2010, 1477, 1-9 (2010).

14. Arnórsson, S., Gunnlaugsson, E. \& Svavarsson, H., The chemistry of geothermal waters in Iceland. II. Mineral equilibria and independent variables controlling water compositions. Geochimica et Cosmochimica Acta 47, 547-566 (1983).

15. Claesson, L., Skelton, A., Graham, C., Mörth, C-M., The timescale and mechanisms of fault sealing and water-rock interaction after an earthquake. Geofluids 7, 1-14 (2007). 
16. Árnason, B., Hydrothermal systems in Iceland traced by deuterium. Geothermics 5, 125-151 (1977).

17. Sveinbjörnsdóttir, Á. E., Johnsen, S. J. \& Arnórsson, S. The use of stable isotopes of oxygen and hydrogen in geothermal studies in Iceland. Proceedings of the World Geothermal Congress 1995, 1043-1048 (1995).

18. Sveinbjörnsdóttir, Á.E., Ármannson, H., Ólafsson, M., Óskarsson, F., Markússon, S. \& Magnúsdóttir, S.,The Theistareykir geothermal field, NE Iceland. Isotopic characteristics and origin of circulating fluids. Procedia Earth and Planetary Science 7, 822-825 (2013).

19. Manga, M. \& Brodsky, E., Seismic Triggering of Eruptions in the Far Field: Volcanoes and Geysers, Annual Reviews of Earth and Planetary Sciences 34, 263-291 (2006).

20. Wang, C.-Y. \& Manga, M., Hydrologic responses to earthquakes and a general metric, Geofluids 10, 206-216 (2010).

21. Elkhoury, J.E., Brodsky, E.E. \& Agnew, D.C. Seismic waves increase permeability, Nature 44, 11351138 (2006).

22. Dobrovolsky, I. P., Zubkov, S. I. \& Miachkin, V. I., Estimation of the size of earthquake preparation zones. Pure and Applied Geophysics 117, 1025-1044 (1979).

23. Rikitake, T., Earthquake prediction: an empirical approach, Tectonophysics 148, 195-210 (1988).

24. Pope, E.C., Bird, D.K. \& Arnórsson, S., Stable isotopes of hydrothermal minerals as tracers for geothermal fluids in Iceland. Geothermics 49, 99-110 (2014).

25. Johnsen, S.J., Dansgaard, W. \& White, J., The origin of arctic precipitation under present and glacial conditions. Tellus 41, 452-468 (1989).

26. Mastin, L.G., Explosive tephra emissions at Mount St. Helens, 1989-1991: The violent escape of magmatic gas following storms? Geological Society of America Bulletin 106, 175-185 (1994).

27. Silver, P.G. \& Valette Silver, N.J., Detection of Hydrothermal Precursors to Large Northern California Earthquakes, Science 257, 1363-1368 (1992).

28. Kristmannsdóttir, H., Alteration of Basaltic Rocks Hydrothermal Activity at $100-300^{\circ} \mathrm{C}$. Proceedings International Clay Conference, Oxford, 359-367 (1978). 
29. Giggenbach, W.F., Geothermal solute equilibria. Derivation of Na-K-Mg-Ca geoindicators, Geochimica et Cosmochimica Acta 52, 2749-2765 (1988).

30. Gislason, S.R. \& Oelkers, E.H., Mechanism, rates, and consequences of basaltic glass dissolution: II. An experimental study of the dissolution rates of basaltic glass as a function of $\mathrm{pH}$ and temperature, Geochimica et Cosmochimica Acta 67, 3817-3832 (2003).

Correspondence and requests for materials should be addressed to Alasdair Skelton.

\section{Acknowledgements}

Lillemor Claesson Liljedahl is acknowledged for initiating our groundwater measurement campaign in northern Iceland. Steven Ingebritsen, Matthew Leybourne and an anonymous reviewer are thanked for insightful and constructive reviews. Amy Whitchurch is thanked for helpful editorial guidance.

\section{Author contributions}

A.S. conceived the project design; H. K., A.E. S. and H-R. G. provided expertise on water-rock interaction in Iceland; H. H. collected the samples; M. A., C-M. M. and H. S. performed the chemical analyses; G. S. and M. A. performed the PHREEQCI modelling; S. J. and E. S. provided expertise on seismicity; I. K. performed the statistical analysis. A.S. wrote the paper with input from all coauthors.

\section{Figure legends}

Figure 1: Tectonic map of northern Iceland.

Caption: This figure shows the Northern Volcanic Zone (NVZ), Húsavík-Flatey Fault (HFF), Grímsey Oblique Rift (GOR), groundwater sampling sites: Hafralækur $\left(65.8725^{\circ} \mathrm{N} 17.4525^{\circ} \mathrm{W}\right.$ : this study) and Húsavík (previous studies) and fault traces (solid lines). Earthquakes of magnitudes 2-5 are shown as orange dots. Locations of earthquakes on September 16, 2002 (M 5.8); September 19, 2012 (M 4.5);

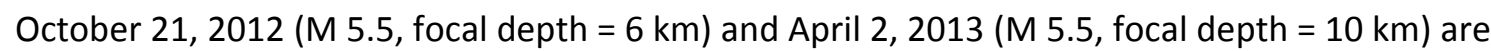


highlighted. Data provided by Icelandic Meteorological Office courtesy of Gunnar Gudmundsson.

243 Focal mechanisms are from the Global CMT Project (http://www.globalcmt.org/).

Figure 2: $\delta^{18} \mathrm{O}-\delta^{2} \mathrm{H}$ plot for groundwater samples from Hafralækur.

245 Caption: This figure compares $\delta^{18} \mathrm{O}-\delta^{2} \mathrm{H}$ values for groundwater samples with GMWL $\left(\delta^{2} \mathrm{H}=8 \times \delta^{18} \mathrm{O}\right.$

$246+10)$. Statistically separable data clusters (1-4) are shown by colored symbols with mean values

247 shown by dashed lines. $2 \sigma$ envelopes are omitted from this figure for clarity, but shown in figure 3.

248 The inset shows inferred three-component mixing between modern day (Holocene) groundwater

$249\left(\delta^{2} \mathrm{H} \sim 70 \%\right.$ ), pre-Holocene groundwater (for which the absolute isotopic composition is not known)

250 and a groundwater component that is affected by water-rock interaction and thus shifted towards

251 fresh basaltic rocks $\left(\delta^{18} \mathrm{O}>+5 \%\right.$ ) .

252

Figure 3: Time series for deviation of $\delta^{2} \mathrm{H}$ from $-126.6 \pm 2.7 \%$, deviation of $\delta^{18} \mathrm{O}$ from GMWL, and $\mathrm{Na}, \mathrm{Si}$ and $\mathrm{Ca}$ concentrations

Caption: Time series for a) deviation of $\delta^{2} \mathrm{H}$ from $-126.6 \pm 2.7 \%$ (see main text for explanation) b) deviation of $\delta^{18} \mathrm{O}$ from GMWL, and c) Na, Si and Ca concentrations are shown. Earthquakes are shown by solid $(M>5)$ and dashed $(M<5)$ red lines. Normally distributed data are shown by open circles $\left(\delta^{2} \mathrm{H}, \delta^{18} \mathrm{O}, \mathrm{Na}\right)$, black circles $(\mathrm{Si})$ and triangles $(\mathrm{Ca})$ with mean values and $2 \sigma$ envelopes. Preseismic maxima are shown by yellow symbols. Data clusters are shown by colored symbols with mean values and $2 \sigma$ envelopes. Pre- and co-seismic changes are shown by arrows. Analytical errors are shown.

\section{Methods}

\section{Sampling procedure}

Groundwater samples have been collected on a weekly basis since October 2008. Separate samples were collected for analysis of isotope values, anions and cations/elements. Of these, only $\mathrm{Na}, \mathrm{Ca}$ and $\mathrm{Si}$ were present in parts-per-million concentrations. The concentration of K was $\sim 1 \mathrm{ppm}$. Samples were filtered through $0.2 \mu \mathrm{m}$ filters into acid-washed LDPE bottles. Concentrated supra-pure $\mathrm{HNO}_{3}$ was added to samples collected for analysis of cations/elements $\left(1 \mathrm{ml} \mathrm{HNO}_{3}\right.$ per $100 \mathrm{ml}$ sample). Samples were refrigerated and stored in Húsavík from where they were shipped to the Department of Geological Sciences, Stockholm University. 
Oxygen $\left(\delta^{18} \mathrm{O}\right)$ and hydrogen $\left(\delta^{2} \mathrm{H}\right)$ isotopic values were measured using a cavity ring down spectroscopy (CRDS) instrument from Los Gatos Research (LWIA model). Both $\delta^{18} \mathrm{O}$ and $\delta^{2} \mathrm{H}$ were normalized so that the difference between VSMOW and SLAP was $-55.5 \%$ for $\delta^{18} \mathrm{O}$ and $428 \%$ for $\delta^{2} \mathrm{H}$. Cation/element concentrations were analysed using a Thermo ICAP 6500 Duo inductively coupled plasma optical emission spectroscopy (ICP-OES) system. Anions were analysed using a Dionex DX-300 ion chromatography system. Temperature, $\mathrm{pH}$ and alkalinity were measured periodically onsite at Hafralækur. The error in analysis of the measurements was better than $\pm 0.6 \%$ o for the $\delta^{2} \mathrm{H}$ values, $\pm 0.1 \%$ or for the $\delta^{18} \mathrm{O}$ values and $\pm 2 \%$ for element concentrations. Charge balance was confirmed using PHREEQCI (http://wwwbrr.cr.usgs.gov/projects/GWC_coupled/phreeqci/) using anion data (supplementary table 1) and alkalinity measured in the field. Total C (supplementary table 1) was calculated from alkalinity using PHREEQCI. Earthquake data was provided by Icelandic Meteorological Office courtesy of Gunnar Gudmundsson.

\section{Statistical analysis}

The Shapiro-Wilk normality test was performed using R (http://www.r-project.org/). This test was used to compare with the null hypothesis that apparent pre-seismic $\delta^{2} \mathrm{H}$ and $\mathrm{Na}$ maxima were part of a normal distribution. This null hypothesis could be rejected with a $p$-value $<10^{-6}$ for $\delta^{2} \mathrm{H}$ and a $p$ value $<10^{-11}$ for $\mathrm{Na}$. The most extreme values (i.e. least negative $\delta^{2} \mathrm{H}$, highest $\mathrm{Na}$ concentration) were removed one at a time and the test was repeated. After removal of the 21 most extreme values for $\delta^{2} \mathrm{H}$ and the 44 most extreme values for $\mathrm{Na}$, normal distribution could no longer be rejected (i.e. $p$-value $>0.05)$. The remaining $\delta^{2} \mathrm{H}$ data were normally-distributed with a mean value of $-126.6 \%$ and a standard deviation $(1 \sigma)$ of $1.34 \%$. The remaining Na data are normally distributed about a gradient of $-0.9 \mathrm{ppm}-\mathrm{Na} /$ year with a standard deviation of $1.02 \mathrm{ppm}$. Only the $\delta^{2} \mathrm{H}$ and Na maxima that coincided with the $M>5$ earthquakes fell outside (above) these normal distributions by $>2 \sigma$ (i.e. $2.7 \%$ for $\delta^{2} \mathrm{H}$ and $2.04 \mathrm{ppm}$ for $\mathrm{Na}$ ).

The following binomial test was used to compare with the null hypothesis that both $\delta^{2} \mathrm{H}$ and $\mathrm{Na}$ maxima occurred randomly and were in fact unrelated to the $M>5$ earthquakes:

$P=P_{H} \cdot P_{N a}$

where $P$ is the $p$-value for both $\delta^{2} \mathrm{H}$ and Na maxima coinciding with $n_{e} \mathrm{M}>5$ earthquakes, and $P_{H}$ and $P_{N a}$ are the respective $p$-values for $\delta^{2} \mathrm{H}$ or $\mathrm{Na}$ maximum coinciding with $n_{e} \mathrm{M}>5$ earthquakes. $P_{H}$ and $P_{N a}$ are calculated from expressions of the form:

$P=\frac{p^{n}(1-p)^{\left(n_{e}-n\right)} n_{e} !}{n !\left(n_{e}-n\right) !}$ 
where $n_{e}$ is the number of $M>5$ earthquakes (2), $n$ is the number of these earthquakes ( 1 or 2 ) which

304 coincide with the $\delta^{2} \mathrm{H}$ or Na maximum and $p$ is given by:

$p=t_{m} / t$

306 where $t$ is the duration of the study (56 months) and $t_{m}$ is the duration of the $\delta^{2} \mathrm{H}$ or Na maximum (3 months or 4 months, respectively).

Using the binomial test given by equations (1-3), we calculated a p-value of $10^{-5}$ for both $\delta^{2} \mathrm{H}$ and $\mathrm{Na}$ maxima (with durations of 3 and 4 months, respectively) coinciding with both $M>5$ earthquakes. On this basis, we reject the null hypothesis. For our time series of 5 years, we can reject the null hypothesis (i.e. p-value $<0.05)$ based on either maxima $\left(\delta^{2} \mathrm{H}\right.$ or $\mathrm{Na}$ ) having coincided with both earthquakes ( $p$-value $<0.005)$ or both maxima $\left(\delta^{2} \mathrm{H}\right.$ and $\mathrm{Na}$ ) having coincided with one of these earthquake ( $p$-value $=0.01$ ). In comparison, one maximum $\left(\delta^{2} \mathrm{H}\right.$ or $\left.\mathrm{Na}\right)$ before one of these earthquakes gives a $p$-value $>0.10$ and fails to confirm a probable association.

315 The Wilcoxon rank sum test was used to compare with the null hypothesis that our $\delta^{18} \mathrm{O}$ data 316 represents one, not four separate populations. Population boundaries were set by non-linear 317 regression of four Gaussian curves to a histogram of the data using DATAFIT

318 (http://www.oakdaleengr.com/datafit.htm). This gave an adjusted coefficient of multiple 319 determination of 0.76 , which compares with 0.08 if the data are treated as a single population. The 320 Wilcoxon rank sum test was then performed using $R$. The null hypothesis could be rejected with $p$ 321 value $<10^{-12}$. This text was also used to confirm that Si and Ca maxima which correlated with the $\mathrm{Na}$ 322 maxima were separable from the remaining data. The null hypothesis was rejected with $p$-value $<10$ 323 5 . 


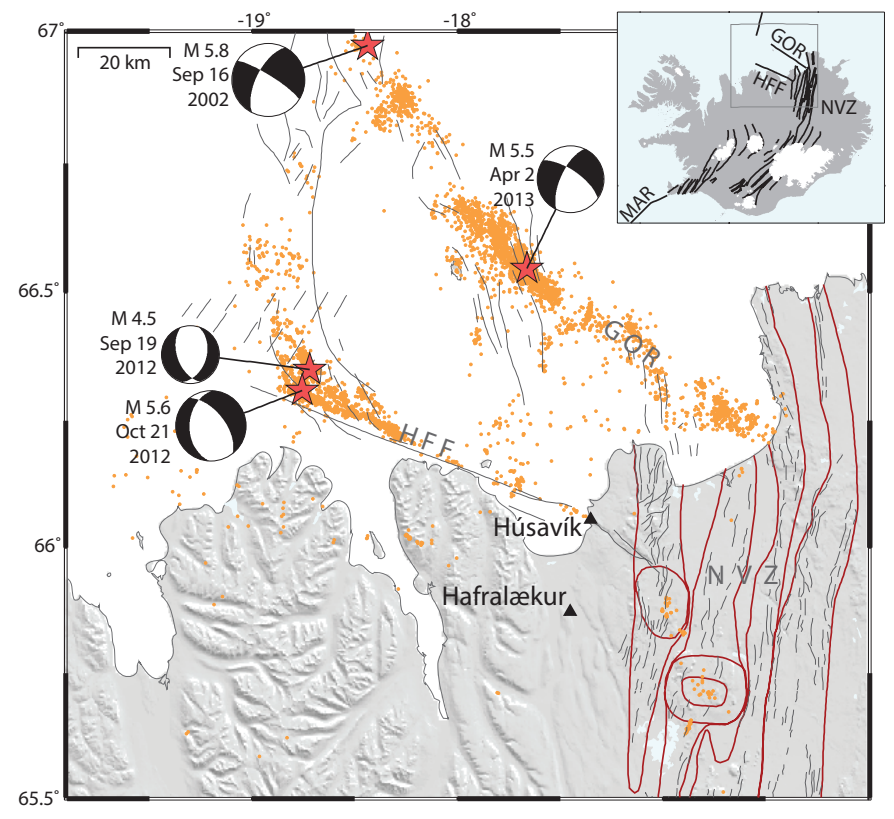




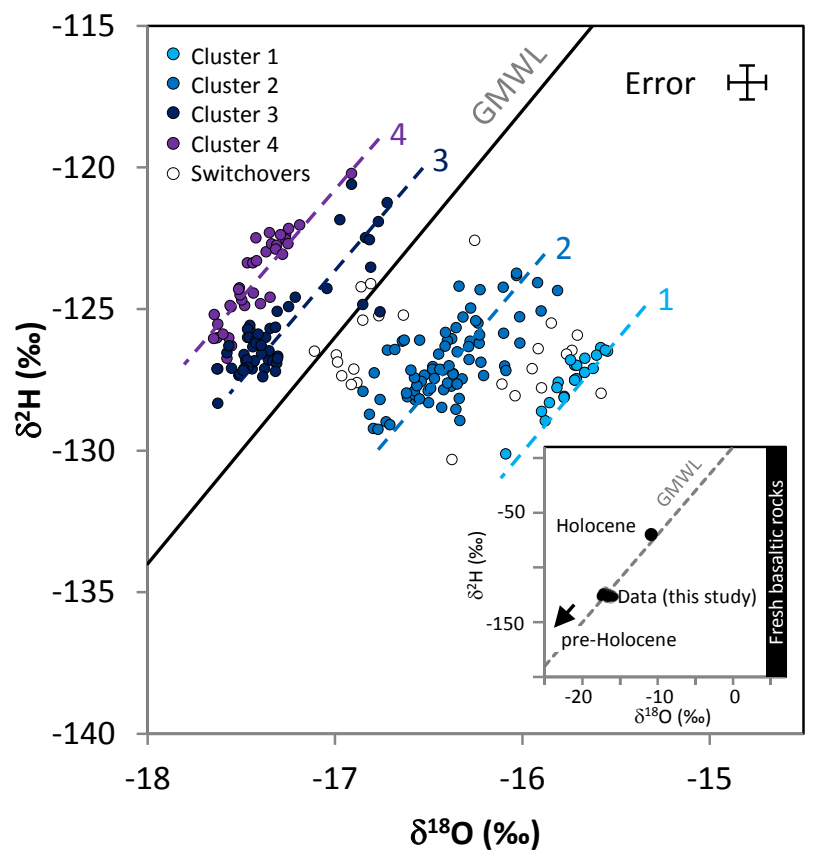


